- RAM, REV. ADM. MACKENZIE, 16(2) • SÃO PAULO, SP • MAR./ABR. 2015 •ISSN 1518-6776 (impresso) • ISSN 1678-6971 (on-line) • http://dx.doi.org/10.1590/1678-69712015/administracao.v16n2p214-244. Submissão: 21 mar. 2014. Aceitação: 30 out. 2014.

\title{
PROPOSIÇÃO DE MÉTODO PARA AVALIAR A MATURIDADE DO PROCESSO DE CENÁRIOS
} NAS ORGANIZAÇÕES

\section{NATHÁLIA MACÊDO DE MORAIS}

Mestra em Administração de Empresas pelo Programa de Pós-Graduação em Administração da Universidade de Fortaleza (PPGA-Unifor).

Gerente do Departamento de Gerência de Desenvolvimento Jurídico da Companhia de Água e Esgoto do Ceará (Gedej-Cagece). Avenida Lauro Vieira Chaves, 1.030, Vila União, Fortaleza - CE - Brasil - CEP $60422-901$

E-mail: nathalia.macedo@gmail.com

\section{SÉRGIO HEIRIQUE ARRUDA CAVALCANTE FORTE}

Doutor em Administração de Empresa pela Escola de Administração de São Paulo da Fundação Getulio Vargas (FGV). Coordenador do Programa de Pós-Graduação em Administração da Universidade de Fortaleza (PPGA-Unifor). Avenida Washington Soares, 1.321, bloco P, sala 17, Edson Queiroz, Fortaleza - CE - Brasil - CEP 6081 1-905 E-mail: sergioforte@unifor.br

\section{ODERLENE VIEIRA DE OLIVEIRA}

Doutora em Administração de Empresas pelo Programa de Pós-Graduação em Administração da Universidade de Fortaleza (PPGA-Unifor).

Professora adjunta do Programa de Pós-Graduação em Administração da Universidade de Fortaleza (PPGA-Unifor).

Avenida Washington Soares, 1.321, bloco P, sala 17, Edson Queiroz, Fortaleza - CE - Brasil - CEP 6081 1-905

E-mail: oderlene@unifor.br

\section{MICHELLEE DO CARMO SOBREIRA}

Mestra em Administração de Empresas pelo Programa de Pós-Graduação em Administração da Universidade de Fortaleza (PPGA-Unifor). Pesquisadora do Programa de Pós-Graduação em Administração da Universidade de Fortaleza.

Rua Osvaldo Cruz, 1.210, ap. 32, Aldeota, Fortaleza - CE - Brasil - CEP 60125-048

E-mail: michellesobreira@gmail.com

Este artigo pode ser copiado, distribuído, exibido, transmitido ou adaptado desde que citados, de forma clara e explícita, o nome da revista, a edição, o ano, e as páginas nas quais o artigo foi publicado originalmente, mas sem sugerir que a RAM endosse a reutilização do artigo. Esse termo de licenciamento deve ser explicitado para os casos de reutilização ou distribuição para terceiros. Não é permitido o uso para fins comerciais. 


\section{RESUMO}

Estudos de cenários são desenvolvidos por governos e organizações como meio para vislumbrar futuros possíveis e assim realizar o traçado de suas estratégias. Ocorre que existem poucas pesquisas que avaliem a efetividade desses estudos. Normalmente o que se encontra na literatura são atributos destinados a avaliar o documento de apresentação do cenário. Nesse sentido, uma abordagem possível é a distinção entre o conteúdo, ou seja, o produto cenário propriamente dito, e o processo que dá suporte à sua elaboração. Nesse contexto teórico, a pesquisa objetivou propor e aplicar um método para avaliar a maturidade do processo de cenários nas organizações. Em consequência, identificaram-se os componentes e subcomponentes principais do processo de cenários que permitam avaliá-los; definiram-se as métricas que indiquem os estágios de maturidade organizacional em cenários; e realizou-se um exercício de aplicação do método por meio de pesquisa a um conjunto de organizações brasileiras selecionadas. Como uma alternativa possível para basear o método proposto, foi utilizado o modelo de maturidade em gerenciamento de projetos (MMGP). Assim, empreendeu-se um estudo multimetodológico, qualitativo e interpretativo para a coleta e interpretação dos dados, constando de levantamento bibliográfico, entrevistas com expertises do meio acadêmico e uso de técnica de análise de conteúdo. Como resultado, obteve-se uma proposta de avaliação do processo de cenários nas organizações, na qual se consideraram as seguintes etapas: preparação, elaboração, produção do documento e utilização. Para determinar qual o estágio alcançado em cenários, os estágios foram assim classificados: inativo, iniciado, padronizado, gerenciado e otimizado, culminando nos níveis de maturidade muito fraco, fraco, regular, bom, ótimo e excelente. O exercício de aplicação do método com I3 organizações brasileiras identificou maturidade regular, revelando a predominância do assunto no setor público, com maiores níveis observados em órgãos nacionais de defesa. O estudo traz contribuições aos campos acadêmico e profissional, pois ao primeiro acrescenta um conhecimento novo, representado por uma proposta de avaliação do processo de cenários; com relação ao segundo, disponibiliza às 
organizações e às consultorias uma metodologia que permita a realização de diagnóstico do processo baseado em cenários, bem como a proposição de ações direcionadas para a melhoria a partir das lacunas objetivamente identificadas.

\section{PALAVRAS-CHAVE}

Cenários. Estratégia. Processos. Gestão de projeto. Maturidade organizacional.

\section{INTRODUÇÃO}

A curiosidade sobre os fatos que ocorrerão no futuro é uma característica humana e que se manifesta desde as mais remotas civilizações. É possível citar como exemplos as profecias bíblicas ou mesmo as crenças milenares na astrologia, nos oráculos e magos como meio de antever acontecimentos e de se preparar para aproveitá-los ou combatê-los.

Na ciência social aplicada, o planejamento de cenários é a ferramenta metodológica utilizada por organizações e governos para vislumbrar os futuros possíveis com o objetivo decidir, no momento presente, os caminhos a seguir para se adequar ao cenário delineado. Esse tipo de planejamento tem se destacado como a ferramenta favorita e mais popular entre os estudos do futuro (Pishvaee, Fathi, \& Jolai, 2008; Sohail, 2002).

Mietzner e Reger $(2005,2007)$ reconhecem que existem poucas pesquisas que objetivem avaliar a qualidade dos cenários e que essa seria uma tarefa de alta complexidade, mas sugerem que uma abordagem possível seja a distinção entre o conteúdo, ou seja, o produto cenário propriamente dito, e o processo que dá suporte à elaboração.

De modo contrário, Bishop (200I) não acredita na possibilidade de se empreender com êxito essa avaliação, pois defende que os estudos de futuro são mais próximos da arte do que da ciência, dado o peso elevado das opiniões de especialistas na construção dos cenários, e, que estes muitas vezes emitem suas opiniões fundamentadas no feeling e não em bases teóricas comprovadas.

Godet e Durance (20II) reforçam que não há interesse em cenários se não são pertinentes, nem coerentes, nem verossímeis, mas reconhecem que a construção coletiva de cenários desejados desempenha um papel de catalisador coletivo, e, nesse caso, o resultado (o cenário) é menos importante que o processo coletivo que a ele conduz, pois, quando se assume o risco de refletir em conjunto sobre o futuro, o importante é colocar as boas questões, a começar por aquelas que não são consensuais, pois perturbam os hábitos e a ordem estabelecidos. 
No Brasil, a utilização de cenários como uma ferramenta de gestão eficaz ainda não atingiu a maioria das pequenas e médias instituições públicas ou privadas. Da mesma forma, para as grandes companhias, ainda é pouco representativo o seu uso, e a análise do cenário ainda não é parte de uma rotina de tomada de decisão. Assim, os casos de sucesso mais representativos ocorreram em empresas estatais, especialmente no setor da energia, e no governo (Porto, Marques, \& Santos, 2010).

Sob o ponto de vista das formas de avaliar o desenvolvimento de um processo, os modelos de maturidade têm usualmente sido aplicados à análise de processos organizacionais para averiguar a plenitude ou perfeição de crescimento ou desenvolvimento (Rosemann \& Bruin, 2005).

De maneira análoga, a maturidade em cenários diz respeito a um estágio em que a organização está suficientemente desenvolvida nesse processo, ou seja, há a consciência disseminada em vários níveis sobre a necessidade, bem como sobre os resultados esperados do processo, e há uma metodologia consolidada para dar suporte à cenarização (Moraes \& Forte, 2012). Para alguns modelos de maturidade, o estágio mais elevado a ser alcançado é aquele em que a organização se torna referência e passa a servir de benchmark para seus pares no mesmo setor econômico ou mesmo para organizações pertencentes a setores distintos (Siqueira, 2005).

Na tentativa de desenvolver um método de avaliação da efetividade dos cenários, surgiram, a princípio, duas questões básicas. A primeira relaciona-se com a qualidade da elaboração dos cenários, e a segunda diz respeito ao uso que é dado ao cenário desenvolvido, em termos de abrangência e efetividade. Assim, vislumbrou-se que poderiam ocorrer diferentes combinações da dialética entre elaboração e uso, em que as organizações podem: I. não elaborar ou não adquirir cenários de qualquer espécie; 2. não elaborar cenários, mas adquiri-los e não os utilizar ou utilizá-los de forma restrita; 3. não elaborar cenários, mas adquiri-los e utilizá-los de forma abrangente e estruturada; 4. elaborar cenários de baixa qualidade e não utilizá-los ou utilizá-los de forma restrita; 5. elaborar cenários de baixa qualidade e utilizá-los de forma abrangente e estruturada; 6 . elaborar cenários de alta qualidade e não os utilizar ou utilizá-los de forma restrita; e 7. elaborar cenários de alta qualidade e utilizá-los de forma abrangente e estruturada.

Essas combinações, exemplificativas e não exaustivas, retratam algumas das possibilidades fáticas e demonstram a dificuldade de se desenvolver uma fórmula que permitisse empreender a avaliação da maturidade das organizações na elaboração e no uso de cenários.

Então, decorrente dessa dificuldade e diante da carência identificada pela academia sobre quais critérios considerar para avaliar cenários ou mesmo sobre o reconhecimento da possibilidade de avaliá-los e diante da popularização dos modelos de maturidade como metodologias efetivas para avaliar o desenvolvimento de processos, questiona-se: Como avaliar a maturidade organizacional 
no processo de cenários?. Assim, a pesquisa buscou atender ao objetivo geral de propor um método para avaliação da maturidade organizacional no processo de cenários, percorrendo os seguintes objetivos específicos: I. identificar os componentes e subcomponentes principais do processo de cenários que permitam avaliá-lo; 2. definir as métricas que indiquem os estágios de maturidade organizacional em cenários; e 3. aplicar o método a um conjunto de organizações.

Dessa forma, o estudo trará contribuições aos campos acadêmico e profissional, pois ao primeiro acrescentará um conhecimento novo, representado por uma evolução nos modelos de maturidade organizacional em cenários; com relação ao segundo, disponibilizará às organizações um framework que permitirá a realização de diagnósticos do processo, bem como a proposição de ações direcionadas para a melhoria a partir das lacunas objetivamente identificadas.

Além desta introdução, a estrutura do trabalho está dividida em referencial teórico composto de uma visão processual de cenários, perspectivas de avaliação do processo, noções de modelos de maturidade como ferramentas de avaliação de processos, comparativo entre o gerenciamento de projetos e o processo de cenários, metodologia, resultados e conclusão.

\section{UMA VISÃO PROCESSUAL APLICAdA A CENÁRIOS}

Processo é qualquer atividade que recebe uma entrada (input), agrega-lhe valor e produz uma saída (output) para um cliente interno ou externo, fazendo uso de recursos da organização para gerar resultados concretos (Harrington, 2006).

Existem diferentes abordagens de como planejar cenários e utilizar a técnica de cenários (Van Der Heijden, 2005). Mas alguns aspectos são muito semelhantes mesmo com conceitos diferentes (Mietzner \& Reger, 2007). Normalmente, começa-se por esclarecer as decisões a serem tomadas, desafiando rigorosamente os mapas mentais que moldam as percepções das pessoas, seguindo-se pela coleta de informação, a partir de várias fontes. Os próximos passos são mais analíticos: relacionam-se com a identificação das forças motrizes, dos elementos predeterminados e das incertezas críticas. Posteriormente, três ou quatro itens compõem o cenário cuidadosamente. Finalmente, os principais eventos ou pontos de inflexão, que conduzem para um cenário em detrimento de outro, são identificados (Mietzner \& Reger, 2005).

Embora não haja um processo padronizado e muitas diferenças possam ser observadas entre as diversas abordagens de elaboração de cenários, em geral, é possível visualizar uma estrutura básica que percorre as seguintes etapas: 
identificação do problema, identificação dos fatores relevantes, classificação e avaliação, elaboração de cenários e tomada de decisão, relacionada à identificação do problema (Bood \& Postma, I998).

De acordo com a norma ISO/IEC I5504-5 (International Organization Standardization \& International Electrotechnical Comission, 2006), que se presta a estabelecer padrões para a realização de avaliações de processos de software, as características necessárias para a existência de um processo são: identificação, denominação, propósito, resultados esperados, prática-base e produtos de trabalho.

Diante desses critérios, pode-se afirmar que não subsistem dúvidas quanto ao processo de cenários, posto que é possível identificá-lo e distingui-lo como um processo empresarial, pois possui denominação própria (cenários) e propósito específico (a antecipação), os resultados esperados dizem respeito às melhorias geradas nos processo de planejamento e de tomada de decisões, as práticas-base referem-se aos aspectos metodológicos que dão suporte à elaboração de um estudo de cenários e os produtos de trabalho são os estudos propriamente ditos.

De forma sintética, é possível representar o processo de cenários pela Figura I.

\section{FIGURA I}

\section{REPRESENTAÇÃO SIMPLIFICADA DO PROCESSO DE CENÁRIOS}

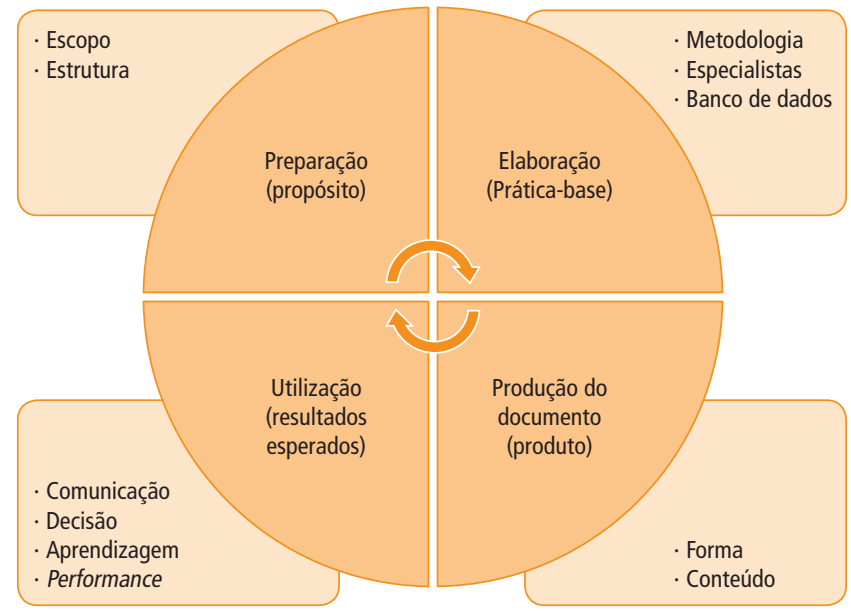

Fonte: Elaborada pelos autores.

- Preparação: essa fase preparatória engloba recursos que poderão influenciar os resultados finais e diz respeito à forma como ocorre o planejamento para realizar os estudos. A estrutura criada e o patrocínio do executivo principal são exemplos de atos preparatórios para a elaboração dos cenários, mas o 
principal refere-se à identificação do propósito para o qual a organização executará o processo (Godet, 2000; Postma \& Liebl, 2005; Mintzberg, Ahlstrand, \& Lampel, 20I0; Roubelat, 2000, 2009; Schoemaker, 1998, 2004, 2005; Snyder \& Schoemaker, 2009; Van Der Heijden, 2005, 2009).

- Elaboração: agrupam-se todas as práticas-base: os métodos, a escolha dos especialistas a serem consultados, a coleta e preservação dos dados e o alinhamento com as demais práticas de gestão, notadamente com o planejamento estratégico (Godet, 20I0; Godet \& Durance, 20II; Postma \& Liebl, 2005; Ratcliffe, 2004, 2007; Roubelat, 2000, 2009; Schoemaker, I998, 2004, 2005; Snyder \& Schoemaker, 2009; Van Der Heijden, 2005, 2009).

- Produção do documento: os produtos de trabalho referem-se à produção do documento tanto na sua forma como no conteúdo (Barbandere \& Iny, 20I0; Bood \& Postma, I998; Chermack, 2006, 20II; Heinecke \& Schwager, I995; Schoemaker, I998, 2004, 2005; Snyder \& Schoemaker, 2009).

- Utilização: os resultados esperados devem estar alinhados com o propósito para o qual o processo foi impulsionado, de modo a provocar um ou alguns dos seguintes resultados: melhoria do processo de comunicação da estratégia, mudança de modelo mental, melhoria do processo decisório e melhoria de performance (Barbandere \& Iny, 2010; Chermack \& Merwe, 2003; Chermack, 2005, 2006, 20II; Fahey \& Randell, I998; Godet, 2010; Godet \& Durance, 20II; Heinecke \& Schwager, I995; Mietzner \& Reger, 2005; Neilson \& Wagner, 2000; Ratcliffe, 2004, 2007; Roubelat, 2000, 2009; Schoemaker, I998, 2004, 2005; Snyder \& Schoemaker, 2009; Van Der Heijden, 2004, 2005, 2009).

Cenários são norteadores para fundamentar estratégias deliberadas, mas devem ser incorporados à gestão estratégica e retroalimentados por meio de um eficaz sistema de inteligência (Marcial, 20I2). Além disso, devem-se observar o caráter, a oportunidade e os condicionantes de estratégias emergentes (Mintzberg, Lampel, Quinn, \& Ghoshal, 2006).

Esses são alguns aspectos que perpassam o processo de elaboração e uso dos cenários pelas organizações. As perspectivas sobre as quais esses aspectos podem ser observados e consequentemente avaliados é o assunto abordado na seção seguinte.

\section{PERSPECTIVAS DE AVALIAÇÃO DO PROCESSO DE CENÁRIOS}

As funções do planejamento de cenários dividem-se entre duas gerações, das quais a primeira pertence às seguintes funções: I. avaliação e seleção de estratégias; 
2. integração de diversos tipos de dados orientados para o futuro; 3. exploração do futuro e identificação de futuros possíveis. As funções da segunda geração são: 4. fazer com que os gestores despertem para as incertezas ambientais; 5. modificar modelos mentais; 6 . provocar e acelerar a aprendizagem organizacional (Bood \& Postman, I998). Bood e Postman (I998) alertam ainda que as funções da segunda geração indicam que algo mais está ocorrendo durante o processo e que o planejamento de cenários extrapolou as funções originais e passou a ter desdobramentos ligados ao desenvolvimento das organizações.

Com base na teoria sobre planejamento de cenários, Chermack (2005, 20II) divide o assunto em cinco unidades - I. cenários, 2. aprendizado, 3. modelos mentais, 4. decisões e 5. performance -, em que as leis de interação entre elas representam as transições do modelo teórico e ocorrem pelas mudanças dos seis estados do sistema, pela atribuição dos valores o ou I a cada etapa da transição. A teoria do planejamento de cenários é posta em movimento por meio da geração de cenários com relevância para uma determinada situação ou problema. Assim, a inatividade representa a situação em que nenhum cenário foi desenvolvido ainda na organização, porém, a partir do primeiro desenvolvimento do processo, abandona-se a inatividade e o aprendizado pode ser positivamente afetado, o que pode provocar alteração nos modelos mentais, que, por sua vez, podem ampliar as competências organizacionais para decidir, e, por último, pode-se chegar a uma melhoria na performance. As unidades teóricas estão retratadas na Figura 2.

\section{FigurA 2}

\section{UNIDADES DE TEORIA DE PLANEJAMENTO DE CENÁRIOS}

\begin{tabular}{|c|c|c|c|c|}
\hline $\begin{array}{c}\text { Cenários } \\
\text { (unidade 1) }\end{array}$ & $\begin{array}{c}\text { Aprendizado } \\
\text { (unidade 2) }\end{array}$ & $\begin{array}{c}\text { Modelos mentais } \\
\text { (unidade 3) }\end{array}$ & $\begin{array}{c}\text { Decisões } \\
\text { (unidade 4) }\end{array}$ & $\begin{array}{c}\text { Performance } \\
\text { (unidade 5) }\end{array}$ \\
\hline
\end{tabular}

Fonte: Chermack (2005).

No que diz respeito à aprendizagem, Van Der Heijden (2005) defende que o planejamento de cenários é uma ferramenta que contribui para o combate de duas patologias que atingem as organizações: a fragmentação e o pensamento grupal. A primeira é comum em organizações em processo de transição, nas quais o grupo está confuso e não há um alinhamento quanto à identidade ou ao pensamento. O segundo costuma apresentar-se quando as organizações estão em contínuo crescimento e o grupo acaba por adquirir um pensamento único e não considerar as ameaças. Em ambos os casos, o planejamento de cenários traz contribuições. Para a patologia da fragmentação, existe a possibilidade de criação 
de um modelo mental (Huff, I990), enquanto, para a patologia do pensamento grupal, abre-se a discussão para "o que pode dar errado?", gerando direcionamento e coordenação para o grupo.

Devem-se considerar as questões dos níveis individuais, grupais e organizacionais de aprendizagem, com seus respectivos conflitos internos, na busca de alinhamentos e consensos (Bido, Godoy, Araujo, \& Louback, 20Io), entretanto, nesse processo, também é salutar a consulta a opiniões externas, que são muito mais importantes do que as visões internas (Godet, 2000).

Para Chermack e Merwe (2003), o planejamento de cenários leva à conversação estratégica formal e, nesse sentido, permite a criação de um fenômeno denominado "memórias do futuro" que é a memorização de possíveis situações que ainda poderão ocorrer. Assim, o tempo requerido para a tomada de decisão é reduzido drasticamente para os detentores dessas memórias de futuro.

Já a melhoria de performance é vista como um resultado primário do sistema de planejamento, em que as outras unidades da teoria de cenários são consideradas como vetores de desempenho. Para esclarecer, cenários, aprendizagem, modelos mentais e as decisões são fatores que afetam o desempenho, mas não se incorporam a ele (Chermack, 2006).

A compreensão da cenarização como um macroprocesso, composto pelas etapas de preparação, elaboração, produção do documento e utilização, e a necessidade alinhamento estratégico (Canépa, Rigoni, \& Brodbeck, 2008) permitem a avaliação dessas etapas por meio de modelo de maturidade, o que será objeto da próxima seção.

\section{MODELOS DE MATURIDAdE PARA AVALIAÇÃO DE PROCESSOS}

O modelo de maturidade ou capability maturity model (CMM) foi proposto pelo Software Engineering Institute da Carnegie Mellon University, para analisar os processos de desenvolvimento de software com o objetivo de avaliar a capacidade organizacional nessa disciplina. Desde então, o CMM tem se popularizado e se estendido para uma série de outras disciplinas, como: gerenciamento de infraestrutura de tecnologia da informação (TI), gestão de arquitetura organizacional, gestão do conhecimento e gerenciamento de projetos (Rosemann \& Bruin, 2005).

Os modelos de maturidade em geral apresentam-se em cinco níveis que tentam retratar qual o posicionamento organizacional e variam do estágio inicial de uma prática ao estágio otimizado, em que cada nível indica uma melhoria na padronização e organização internas. Outros modelos avaliam o avanço não em termos de níveis ou de graus, mas em termos de percentual de maturidade 
conquistado desde a última avaliação. O organizational project management maturity model ( $\left.\mathrm{OPM}_{3}\right)$, do Project Management Institute (PMI), é um dos modelos que avaliam a maturidade a partir de um gradiente (Harrison, 2006).

Para avaliar a maturidade em gerenciamento de projetos, foram propostos modelos mais universais do que aqueles associados às áreas de desenvolvimento e engenharia de software. Dois modelos conceituais têm sido mais amplamente adotados: o project management maturity model (PMMM), proposto por Kerzner (2006), e o OPM3, proposto pelo PMI (Bouer \& Carvalho, 2005).

No Brasil, desenvolveu-se o modelo de maturidade em gerenciamento de projetos (MMGP), apresentado por Prado (2010), que se caracteriza por: utilizar os mesmos níveis do modelo desenvolvido pela Carnegie Mellon University (de I a 5), conforme mostra a Figura 3; privilegiar a simplicidade (questionários com 40 questões); buscar a universalidade (ser aplicável a qualquer tipo de organização); relacionar a maturidade da organização com sua capacidade de executar projetos com sucesso; contemplar seis dimensões (aspectos fundamentais); abranger processo, pessoas, tecnologia e estratégias.

\section{FIGURA 3}

\section{MODELO DE MATURIDADE EM GERENCIAMENTO}

DE PROJETOS (MMGP)

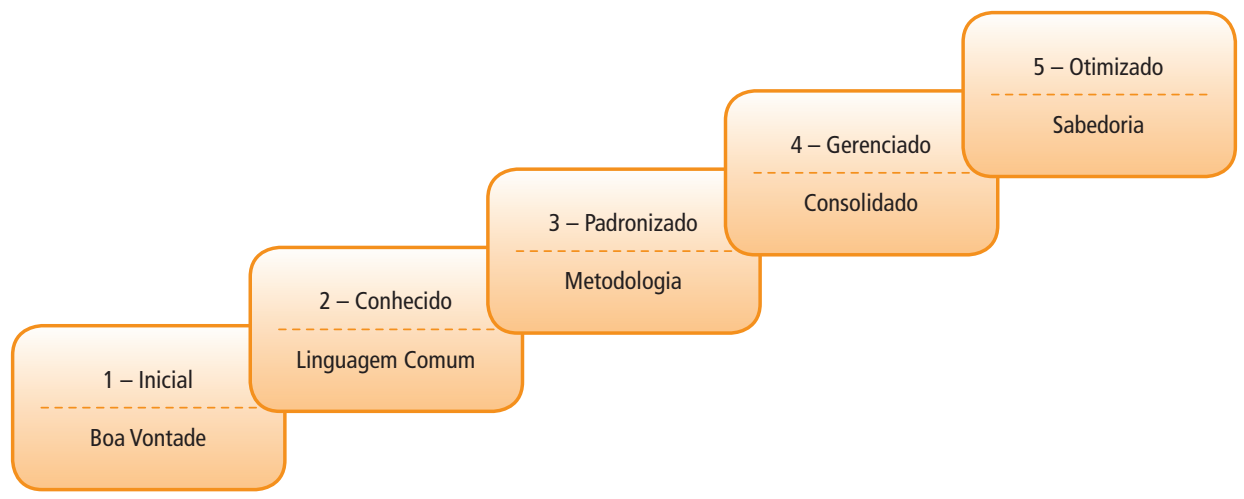

Fonte: Prado (2010).

Pelo modelo proposto por Prado (20I0), as dimensões (competência técnica e contextual, metodologia, informatização, estrutura organizacional, alinhamento com estratégias, competência comportamental) estão presentes em cada nível de maturidade, porém o que caracterizará o nível em que a organização se encontra será a pontuação obtida pela aplicação de questionários que identificam a aderência dessa pontuação a um determinado nível. 
De maneira análoga, para propor um método que identifique a maturidade no processo de cenários, é necessário identificar as dimensão que deverão estar presentes em cada nível e como se espera que seja o comportamento organizacional em cada nível. Antes, porém, é necessário compreender o que aproxima o processo de cenários do processo de gerenciamento de projetos.

\subsection{O GERENCIAMENTO DE PROJETOS E O PROCESSO DE CENÁRIOS}

Projetos são definidos como esforços temporários para criar um produto, serviço ou resultado exclusivo. Por sua vez, o gerenciamento de projetos é um processo que consiste em aplicar conhecimentos, habilidades, ferramentas e técnicas às atividades de um projeto a fim de atender aos seus requisitos. Esse gerenciamento se dá pela aplicação e integração apropriada de 47 processos agrupados de forma lógica entre as fases: iniciação, planejamento, execução, encerramento e monitoramento e controle (Project Management Institute, 20I2).

De modo similar, o processo de cenários também envolve a aplicação de conhecimentos, habilidades, ferramentas e técnicas encadeados para o alcance de um objetivo. Por essa razão, adotou-se um modelo de maturidade em gerenciamento de projetos para desenvolver um método de avaliação do processo de cenários.

Para esclarecer a comparação realizada entre os dois processos (elaboração e uso de cenários e gerenciamento de projetos), a seguir, estão relacionadas na Figura 4 as etapas encontradas em ambos, de acordo com a similaridade identificada.

\section{FigurA 4}

\section{ANALOGIA ENTRE OS PROCESSOS DE GERENCIAMENTO} DE PROJETOS E DE CENÁRIOS

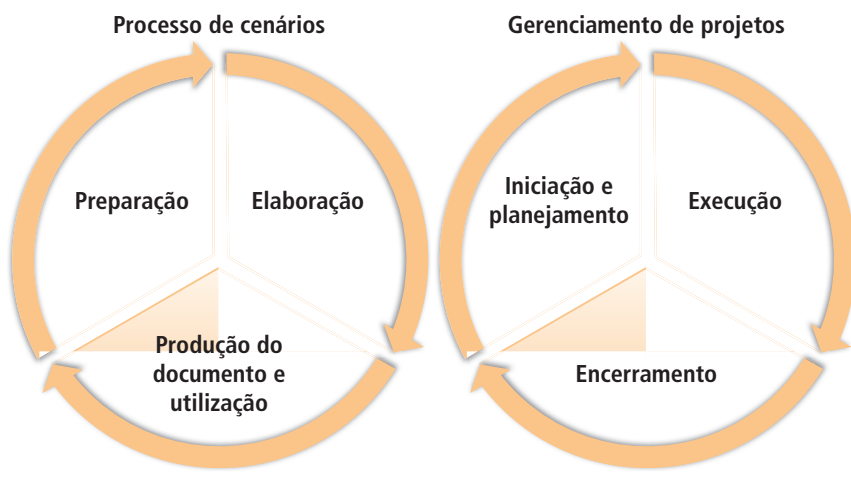

Fonte: Elaborada pelos autores. 
É possível observar que os grupos de processo iniciação, por representarem todo o esforço inicial de planejamento e documentação do gerenciamento de projetos, apresentam correspondência com a etapa do processo de cenários denominada preparação.

Os grupos de processos iniciação e planejamento procuram identificar requisitos, e as partes interessadas (stakeholders), definir o escopo, os recursos humanos necessários, além de se ocuparem do planejamento de tempo (cronograma), custos, riscos, contratações etc. para o desenvolvimento do projeto. A preparação no processo de cenários, da mesma forma, buscará identificar o escopo e a estrutura necessária para o estudo, para qual finalidade será desenvolvido, quem são as partes interessadas (alta administração, média gerência, clientes etc.) e qual o seu nível de envolvimento, quais serão os recursos necessários para o desenvolvimento dos cenários (setores, comitês) e qual a capacitação necessária para as equipes internas, enfim todo o planejamento que precede a etapa de elaboração e que, portanto, guardará semelhança com o planejamento de um projeto, conforme apresentado na Figura 5 .

\section{FIGURA 5}

\section{COMPARATIVO ENTRE AS ETAPAS DE PREPARAÇÃO \\ E DE INICIAÇÃO E PLANEJAMENTO}

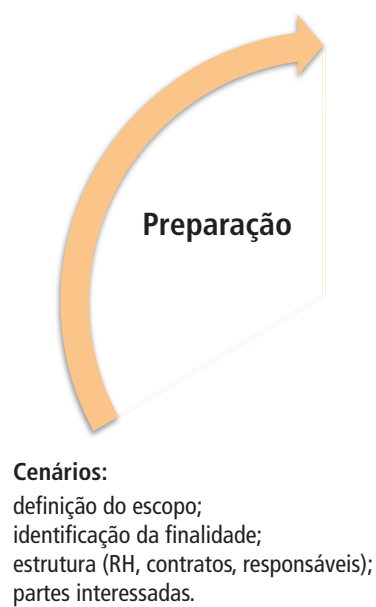

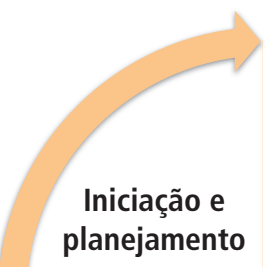

Gerenciamento de projetos: identificação de requisitos; definição do escopo; recursos ( $\mathrm{RH}$, contratos, responsáveis); elaboração de cronogramas; partes interessadas.

Fonte: Elaborada pelos autores.

O grupo de processos denominado execução corresponde pela natureza das atividades à etapa elaboração do processo de cenários, em que ambas serão responsáveis, por meio da coordenação de pessoas e recursos, pela elaboração do 
trabalho que fora definido no planejamento/preparação (Figura 6). A metodologia de desenvolvimento de cenários será aplicada nessa etapa, porém já deve ter sido selecionada na etapa de preparação, assim como na execução de um projeto. A construção e validação do produto ocorrem a partir da metodologia escolhida durante o planejamento.

\section{FIGURA 6}

COMPARATIVO ENTRE AS ETAPAS DE ELABORAÇÃO E EXECUÇÃO

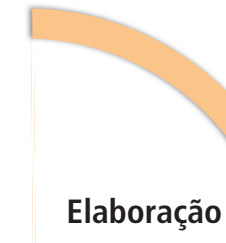

Cenários:

aplicação da metodologia; contato com especialistas:

formação ou atualização do banco de dados.

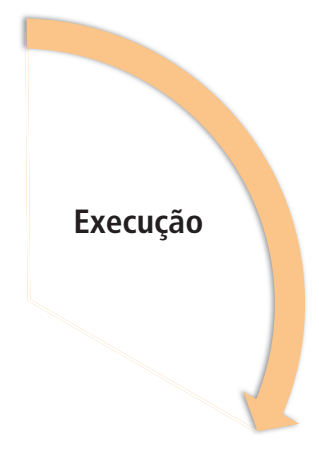

Gerenciamento de projetos:

realização do trabalho definido no planejamento;

construção e validação do produto.

Fonte: Elaborada pelos autores.

Os processos do grupo encerramento consistem nos executados para finalizar todas as atividades, visando completar formalmente o projeto ou a fase, ou ainda obrigações contratuais. Nessa fase, podem ocorrer as seguintes atividades: obter aceitação do cliente ou patrocinador; realizar uma revisão pós-projeto ou de fase final; registrar os impactos da adequação de cada processo; documentar lições aprendidas; arquivar todas as informações importantes no banco de dados apropriado para que possam ser utilizados em outras oportunidades; e encerrar as aquisições (Project Management Institute, 20I2).

Já a conclusão do processo de cenários dar-se-á por duas formas distintas: a primeira diz respeito à produção do documento (finalidade imediata do processo de cenários) e a segunda abrange todos os aspectos relacionados à utilização do estudo gerado (comunicação, aplicação na tomada de decisão, melhoria da aprendizagem e da performance).

O comparativo entre o encerramento do processo de gerenciamento de projetos e a conclusão do processo de cenários está representado na Figura 7. 


\section{FIgURA 7}

\section{COMPARATIVO ENTRE AS ETAPAS DE PRODUÇÃO DO DOCUMENTO/UTILIZAÇÃO E ENCERRAMENTO}

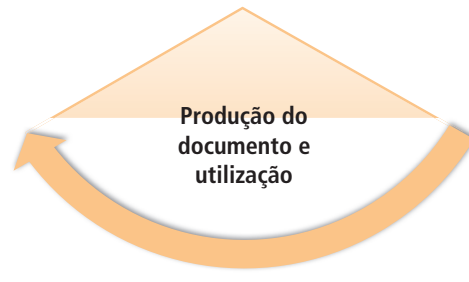

Cenários:

comunicação dos cenários; aplicação na tomada de decisão; melhoria da aprendizagem; melhoria da performance.

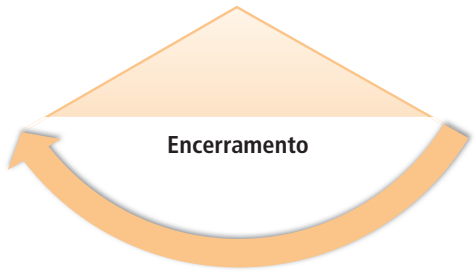

Gerenciamento de projetos:

obter aceitação do cliente/patrocinador; documentar lições aprendidas;

arquivar informações no banco de dados; encerrar aquisições.

Fonte: Elaborada pelos autores.

Observe-se que, em ambos os casos, privilegiam-se, na conclusão dos processos, a comunicação (obter aceites, registrar informações, realizar revisões) e a melhoria da aprendizagem (registro de lições aprendidas, melhoria do banco de dados, registro de impactos) visando com isso à melhoria na tomada de decisão ou mesmo no desempenho de novos projetos ou de outros resultados da organização.

O grupo de processo de monitoramento e controle é responsável por observar e mensurar o desempenho do projeto de forma periódica, para verificar variações em relação ao planejamento. Embora não retratado no processo de cenários, entende-se que o monitoramento e o controle são inerentes a todos os processos gerenciais.

\section{METODOLOGIA DE PESQUISA}

Para desenvolvimento de um modelo de maturidade, Bruin, Freeze, Kulkarni e Rosemann (2005) sugerem a adoção da metodologia exposta na Figura 8.

\section{FIGURA 8}

\section{FASES DE DESENVOLVIMENTO DE UM MODELO DE MATURIDADE}

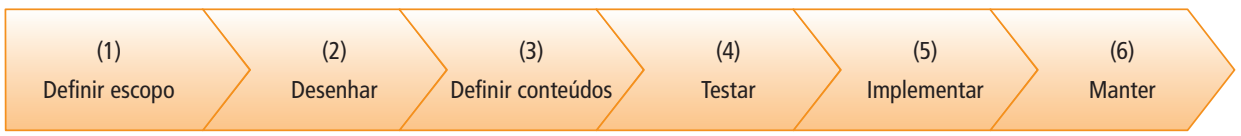

Fonte: Bruin et al. (2005). 
A definição do escopo e o desenho do modelo ocorreram nas fases i e 2 da pesquisa, conforme exposto no Quadro I.

\section{QUADRO I}

DECISÕES SOBRE O ESCOPO E O DESENHO DO MODELO DE MATURIDADE EM PLANEJAMENTO DE CENÁRIO

\begin{tabular}{|c|c|}
\hline CRITÉRIO & CARACTERÍSTICA \\
\hline Foco & - Específico - cenário \\
\hline Stakeholders & - Misto (academia e profissionais) \\
\hline Público & - Interno (executivos, média gerência) \\
\hline Método de aplicação & $\begin{array}{l}\text { - Autoavaliação (questionários serão disponibilizados para } \\
\text { preenchimento) }\end{array}$ \\
\hline Condutor da aplicação & - Interno ou externo \\
\hline Entrevistados & - Gestores \\
\hline Abrangência & $\begin{array}{l}\text { - Múltiplas entidades de múltiplas regiões (organizações brasileiras } \\
\text { que utilizem o planejamento de cenários }\end{array}$ \\
\hline
\end{tabular}

Fonte: Elaborado pelos autores.

A partir dessas decisões, a pesquisa prosseguiu para a fase 3, que se refere ao conteúdo, decisões de o que deve ser mensurado e como. Nessa etapa, foi necessário identificar os principais componentes e subcomponentes do processo de cenários que são mutuamente exclusivos e coletivamente exaustivos, o que se realizou com extensa revisão da literatura e ouvindo opiniões de experts. Após a criação de uma lista inicial, realizaram-se consultas para validá-la. Essas consultas foram realizadas com especialistas do meio acadêmico em dois momentos distintos:

- Momento 1: quando os especialistas relacionaram de forma livre os componentes e subcomponentes.

- Momento 2: quando os especialistas validaram a categorização desenvolvida e as relações entre componentes e subcomponentes.

Para identificação dos experts da academia nacional, foi realizada pesquisa na base de publicações de eventos da Associação Nacional de Pós-Gradução e Pesquisa em Adminstração (Anpad), entre 200I e 20II, utilizando as palavras: 
“cenários", "prospectivos" e "prospecção", bem como o radical "prospec", e obteve-se uma relação inicial, a qual, depois de analisada de acordo com o conteúdo e a pertinência ao objeto da pesquisa, resultou na seleção de 3I trabalhos.

A partir dos trabalhos identificados, foi realizada consulta aos currículos disponibilizados na plataforma Lattes do Conselho Nacional de Desenvolvimento Científico e Tecnológico (CNPq), para verificar a titulação e linha de pesquisa dos autores, bem como o respectivo contato.

Assim, inicialmente, listaram-se 62 especialistas, cujo critério de escolha foi ter publicação sobre o tema na base de dados dos eventos da Anpad nos últimos dez anos. A partir dessa primeira seleção, foram pesquisados por meio da plataforma Lattes aqueles que possuíam o título de doutor ou eram estudantes de doutorado. Obteve-se o total de 4I especialistas que representava a população que deveria ser consultada.

Da lista de 4I especialistas identificados, obteve-se o endereço eletrônico de 37, e, em três casos, ocorreu falha no envio. Dessa forma, houve o envio efetivo de consulta, entre os meses de outubro e novembro de 201 I, em 34 casos.

Ao final, houve retorno de nove respostas de pesquisadores com titulação obtida nas seguintes universidades: Universidade de Trás-os-Montes e Alto Douro (Utad), University of New Hampshire, Universidade de São Paulo (três), Université Sorbonned Nouvelle - Paris 3, Universidade Federal Rural do Rio de Janeiro (UFRRJ), Université de Technologie de Compiègne (UTC) e Universidade Federal de Pernambuco.

No momento I, aos especialistas foram encaminhadas, via endereço eletrônico, perguntas abertas semiestruturadas, em outubro de 20II, para identificar componentes e subcomponentes do processo que permitissem empreender a avaliação da maturidade.

O conteúdo das respostas foi submetido à análise de conteúdo, cujo primeiro passo, da preparação dos dados, envolveu a codificação dos sujeitos envolvidos na pesquisa para preservar a identidade dos participantes. O código utilizado foi "E", de "especialista", seguido do numeral sequencial a partir do ooı. Foram codificados os participantes de Eoor até Eoog. A partir daí, iniciou-se o processo de análise do conteúdo das mensagens que congregou as seguintes etapas: I. pré-análise; 2. exploração do material; 3. tratamentos dos resultados, inferência e interpretação (Bardin, 2009).

Ainda com relação à fase 3 , fez-se necessário determinar como mensurar a medida de maturidade, o que significou desenvolver o próprio instrumento. Mensuração, segundo Malhotra (2006), é a atribuição de números ou outros símbolos a características de um dado objeto e não ao objeto propriamente dito. Com efeito, nessa fase, iniciou-se o desenvolvimento do questionário para avaliação do 
processo de cenários, o qual adotou como insumo teórico o modelo de desenvolvimento da teoria de Chermack (2006) e o MMGP de Prado (2010), além de todo o quadro referencial, que permitiu a identificação dos componentes e subcomponentes do processo, adicionadas as opiniões dos especialistas.

Nesta pesquisa, foi utilizada a triangulação dos dados, confrontando as opiniões da academia nacional com a teoria, com o propósito de chegar à resposta à questão de pesquisa e e atender aos objetivos estipulados no início do estudo (Vergara, 20I3). Nesse sentido, depois de elaborada a primeira categorização dos dados, esta foi novamente submetidas aos especialistas, com o objetivo de validar as etapas, os componentes e subcompontes do processo.

Assim, em março de 20I2, após nova revisão de literatura com o objetivo de confirmar as respostas dos especialistas, realizou-se nova consulta (momento 2). Nessa ocasião, foram encaminhados aos nove especialistas que participaram da primeira consulta questionários, em planilha do software Excel, contendo 25 afirmações nas quais deveriam optar por um número de i a 5, de acordo com o grau de concordância com a sentença, além de arquivo-texto contendo as definições operacionais para cada nível de maturidade do método proposto, com o objetivo de validar as definições e relações apresentadas entre os níveis e as dimensões.

A partir da validação realizada no momento 2, foi concluída a primeira versão do questionário de avaliação da maturidade contendo dez perguntas para cada nível, no formato de questões de múltipla escolha (a, b, c, d e e), valendo Io, $7,4,2$ e o pontos, respectivamente, com o total de pontos obtido de acordo com a fórmula:

Avaliação Final $=($ IO० + total de pontos $) /$ IO०.

Cada pergunta aborda um aspecto da etapa do processo (preparação, elaboração, produção do documento e utilização) válida para aquele nível. As opções para responder aos quesitos propostos estão dispostas em uma escala Likert, em que:

- $\quad$ I: diz respeito à situação de maior desenvolvimento.

- 2: representa situação discretamente inferior à apresentada em I.

- 3: a situação é significativamente inferior à apresentada em I.

- 4: o desenvolvimento do assunto está em estudo ou em implementação.

- 5: o assunto é ignorado ou nada tem sido feito para o desenvolvimento daquele aspecto investigado.

De acordo com o modelo de Prado (2010), os resultados possíveis de maturidade são apresentados no Quadro 2. 


\section{QUADRO 2}

INTERPRETAÇÃO DO RESULTADO DA MATURIDADE

\begin{tabular}{lcc}
\hline AVALIAÇÃO FINAL & CONCEITO & Muito fraca \\
\hline Até 1,6 & Fraca & Regular \\
\hline Acima de 1,60 e abaixo de 2,60 & Boa \\
\hline Acima de 2,60 e abaixo de 3,20 & Ótima \\
\hline Acima de 3,20 e abaixo de 4,00 & Excelente \\
\hline Acima de 4,00 e abaixo de 4,60 & Acima de 4,60 & Pro \\
\hline
\end{tabular}

Fonte: Prado (2010).

A partir dos pontos obtidos, é identificado o perfil de aderência, cujo percentual de aderência dos níveis 2, 3, 4 e 5 corresponde ao percentual obtido no teste de avaliação de maturidade.

De acordo com o modelo MMGP, a aderência é assim considerada a partir do percentual obtido, conforme Quadro 3.

Esses percentuais refletem quão bem a organização se posiciona nos requisitos daquele nível específico. Dessa forma, quanto maior for o perfil de aderência a um determinado nível de maturidade, maior será a possibilidade de a organização possuir características desse nível. No entanto, quanto menor for o perfil de aderência, maiores serão o foco e a necessidade de a empresa desenvolver ações para melhorar a pontuação naquela dimensão, de forma a aumentar seu nível de maturidade.

\section{QUADRO 3}

CONCEITOS DOS PERCENTUAIS DE ADERENCIA

\begin{tabular}{lcc}
\hline PERCENTUAL & CONCEITO \\
\hline Até $20 \%$ & Fraca & Regular \\
\hline Acima de $20 \%$ e abaixo de $40 \%$ & Boa \\
\hline Acima de $40 \%$ e abaixo de $70 \%$ & Ótima \\
\hline Acima de $70 \%$ e abaixo de $90 \%$ & Total \\
\hline Acima de $90 \%$ e até $100 \%$ & \\
\hline
\end{tabular}

Fonte: Prado (2010). 
De acordo com a recomendação de Bruin et al. (2005), foi realizada ainda a fase 4 para desenvolvimento da metodologia de identificação da maturidade em cenários que consistiu na realização de testes. Nesse sentido, foram contactadas organizações para aplicação do questionário, com preliminar apresentação das definições operacionais sobre cada nível de maturidade, solicitando-se que, a partir do informado, a organização informasse o nível que melhor a identificasse. Após a realização dessa opção, o questionário era aplicado com o propósito de identificar o nível apresentado e compará-lo ao que fora previamente informado.

As organizações foram consultadas de forma remota ou presencial. As organizações que responderam ao questionário por via remota (endereço eletrônico) foram intencionalmente selecionadas, tendo em vista a prévia identificação por terem sido citadas em revisão de literatura ou em sites de consultorias especializadas. As organizações que respodenram de forma presencial foram consultadas de forma espontânea durante a realização do evento I Encontro Brasileiro de Prospectiva e Planejamento Estratégico, ocorrido em Brasília, entre os dias 23 e 25 de abril de 2012 . Ao todo, I3 organizações brasileiras se disponibilizaram a participar do teste da metodologia, quatro de forma remota e nove de forma presencial, assim distribuídas: uma organização privada, cinco organizações da administração indireta, quatro da administração direta e três do terceiro setor.

\section{RESULTAdOS E DISCUSSÃO}

\section{PROPOSIÇÃO DO MÉTODO: OPINIÃO DOS ESPECIALISTAS - MOMENTO 1}

De modo geral, as respostas dos especialistas corroboraram os aspectos relacionados pela literatura, uma vez que demonstraram entendimento do objeto de estudo e trouxeram contribuições não só para validar o que estava posto pela revisão de literatura, mas também para acrescentar outros pontos de vista e pressupostos.

Assim, foi utilizada uma abordagem individual e não estruturada, visando assegurar a confidencialidade dos entrevistados sobre as informações obtidas. A partir da aplicação da análise de conteúdo às entrevistas, identificaram-se os seguintes fatores relacionados pelos entrevistados à maturidade em planejamento de cenários: I. grau de aceitação pela organização; 2. metodologia; 3. tempo de uso (ciclos de experiência); 4. competências técnicas e gerenciais; 5. acesso à informação (networking); e 6. resultados/efetividade do processo.

As opiniões convergiram para o entendimento de que a maturidade da organização em utilizar o processo seria expressa pela adoção do modelo como um entendimento efetivo de que é a melhor maneira de obter resultados sustentáveis 
em curto, médio e longo prazos, o que conduz ao entendimento de que o processo não só é aceito pela organização, como também há o patrocínio pela alta administração, o que se traduz como o fator aceitação.

A metodologia foi citada pelos especialistas como a expressão máxima de maturidade da organização no processo. Afirmou-se, em pelo menos um dos casos, que a maturidade seria expressa pela incorporação de uma metodologia utilizada de forma sistemática e pela integração com outras práticas organizacionais. Há a ressalva, porém, para o fato de que algumas organizações utilizam cenários com o foco na inovação dissociado de seu planejamento, o que Godet e Durance (20II) denominam de muitos cenários e poucos projetos endógenos, representando exatamente essa dissociação entre os cenários e a implementação das ações estratégicas.

Ainda quanto à metodologia, observa-se que a opinião dos especialistas está perfeitamente alinhada com as constatações de Kerzner (2006) e Prado (20I0), no que diz respeito à maturidade em gerenciamento de projetos, quando afirmam que o maior grau de dificuldade para evoluir na escala de maturidade se encontra no desenvolvimento de uma metodologia, pois requer uma cultura corporativa consolidada em gestão de projetos.

Um dos aspectos metodológicos destacados pelos especialistas é a análise de natureza participativa envolvendo empregados e consultores qualificados, fato que se alinha com o pensamento de vários autores, mormente aqueles que defendem o planejamento de cenários como uma ferramenta a serviço da aprendizagem organizacional ou que a aprendizagem é mais eficaz quando resulta de formas participativas de planejamento (Buarque, 2003; Chermack, 2005, 2006, 20II; Neilson \& Wagner, 2000, Morgan, I996; Ratcliffe, 2004, 2007; Roubelat, 2000, 2009; Schoemaker, I998, 2004, 2005; Snyder \& Schoemaker, 2009; Van Der Heijden, 2005, 2009).

As referências ao tempo de uso apareceram relacionadas com a incorporação de uma metodologia e ao seu uso de maneira sistematizada, ou por ciclos de aprendizado, isto é, número de vezes/ciclos em que a organização já desenvolveu o processo de elaboração de cenários.

Alguns especialistas entendem a maturidade como função das competências técnicas e gerenciais do capital intelectual da organização. Assim, os tomadores de decisão devem possuir as seguintes características: flexibilidade a mudanças de curso, tendência a assumir riscos, compreensão nítida do conjunto informacional relevante (informações passadas, presentes e futuras relevantes para as atividades da organização), além de estabilidade da equipe que conduz o processo.

Outros dois pontos relacionados foram acesso à informação e avaliação dos resultados alcançados e o grau de aproveitamento obtidos dos resultados desses esforços nas práticas de planejamento estratégico da organização. O acesso à 
informação e aos experts pode ser comparado com o que aparece no nível 4 do modelo MMGP, de Prado (20I0), e se refere a organizações que têm os processos consolidados e que aperfeiçoam o modelo por meio da coleta e da análise de um banco de dados sobre projetos executados, portanto o acesso à informação passa pela disponibilidade e qualidade dos bancos de dados da organização.

Essas foram as opiniões colhidas do grupo de especialistas consultados, todavia Bruin et al. (2005) recomendam que, na fase de definição do conteúdo de um modelo de maturidade, além de a escolha dos componentes ter por base revisão de literatura e realização de entrevistas, também seja utilizada a técnica Delphi ou mesmo grupos focais para a definição de componentes. Partindo dessa orientação, os especialistas foram novamente consultados, dessa vez para validar a categorização de etapas, componentes e subcomponentes do processo, cujos os resultados são descritos a seguir.

\subsection{PROPOSIÇÃO DO MÉTODO: OPINIÃO DOS ESPECIALISTAS - MOMENTO 2}

No momento 2 da consulta aos especialistas, apresentaram-se 25 questões que representavam a síntese da categorização dos componentes e subcomponentes do processo que foram identificados pela revisão de literatura e pela primeira consulta aos especialistas. Dos nove especialistas consultados, sete responderam e dois se abstiveram. Dos sete questionários respondidos, sete foram considerados válidos. De forma sintética, as etapas, os componentes e subcomponentes do processo identificados pela revisão de literatura e validados pelos especialistas estão representados pelo Quadro 4.

QUADRO 4

ETAPAS, COMPONENTES E SUBCOMPONENTES

DO PROCESSO DE CENÁRIOS

\begin{tabular}{lll}
\hline ETAPA & COMPONENTE & SUBCOMPONENTE \\
\hline \multirow{3}{*}{ Escopo } & - Aceitação pela organização \\
& - Alinhamento com a cultura organizacional \\
& - Finalidade \\
\cline { 2 - 3 } Preparação & - Competências \\
& - Setores responsáveis \\
& - Comitês envolvidos \\
& & - Contratação de consultorias \\
\hline
\end{tabular}

(continua) 
QUADRO 4 (CONCLUSÃO)

\section{ETAPAS, COMPONENTES E SUBCOMPONENTES DO PROCESSO DE CENÁRIOS}

\begin{tabular}{|c|c|c|}
\hline ETAPA & COMPONENTE & SUBCOMPONENTE \\
\hline \multirow[t]{3}{*}{ Elaboração } & Metodologia & $\begin{array}{l}\text { - } \text { Ciclos de experiência } \\
\text { - Natureza } \\
\text { - Informatização } \\
\text { - Integração com a gestão estratégica } \\
\text { - Organização de reuniões }\end{array}$ \\
\hline & Rede de especialista & $\begin{array}{l}\text { - Importância da opinião } \\
\text { - Origem do especialista }\end{array}$ \\
\hline & Banco de dados & - Amplitude e qualidade do banco de dados \\
\hline \multirow[b]{2}{*}{$\begin{array}{l}\text { Produção do } \\
\text { documento }\end{array}$} & Forma & $\begin{array}{l}\text { - Estética } \\
\text { - Relação entre caracteres e eventos (diagramas) }\end{array}$ \\
\hline & Conteúdo & $\begin{array}{l}\text { - Estímulo à criatividade } \\
\text { - Plausibilidade } \\
\text { - Relevância } \\
\text { - Transparência } \\
\text { - Rastreabilidade }\end{array}$ \\
\hline \multirow{4}{*}{ Utilização } & Comunicação & $\begin{array}{l}\text { - Criação de vocabulário comum } \\
\text { - Forma de avaliação dos cenários } \\
\text { - Disseminação }\end{array}$ \\
\hline & Decisão & $\begin{array}{l}\text { - Grau de confiança nas decisões tomadas } \\
\text { - Eficiência e eficácia das decisões } \\
\text { - Redução de tempo para a tomada de decisões } \\
\text { - Novos insights } \\
\text { - Impacto na análise ambiental } \\
\text { - Alinhamento dos projetos estratégicos }\end{array}$ \\
\hline & Aprendizagem & $\begin{array}{l}\text { - Desenvolvimentos de competências } \\
\text { - Estudo dos insucessos } \\
\text { - Gestão do conhecimento } \\
\text { - Melhoria contínua }\end{array}$ \\
\hline & Performance & $\begin{array}{l}\text { - Vantagens competitivas geradas } \\
\text { - Visibilidade na comunidade empresarial }\end{array}$ \\
\hline
\end{tabular}

Fonte: Elaborado pelos autores. 
As etapas, os componentes e subcomponentes do processo embasaram a elaboração do questionário, o qual é composto de uma questão inicial que contextualiza o respondente acerca dos possíveis níveis de maturidade em cenários identificados nas organizações, seguida de solicitação para que o respondente indique qual o nível que mais bem define a situação vivenciada em sua organização. Na sequência, o respondente é convidado a responder a 40 questões que objetivam identificar o nível real de maturidade e que permitirão posteriormente confrontá-lo com a resposta inicial.

Ainda quanto ao desenvolvimento do instrumento de coleta, que teve sua estrutura básica validada na segunda consulta aos especialistas, realizou-se um pré-teste que foi submetido duas vezes à análise de uma das organizações identificadas no rol da população-alvo de organizações brasileiras que adotam o processo de cenários.

\subsection{APLICABILIDADE DA METODOLOGIA}

A maturidade média no processo de cenários, nas organizações brasileiras que responderam à pesquisa, é de 2,77, o que corresponde a uma maturidade regular, possuindo a distribuição de aderência expressa pela Tabela I.

\section{TABELA I}

PERFIL DE ADERENCIA AOS NÍVEIS DE MATURIDADE

\begin{tabular}{lc|c|c|c|c|c|c|c|c|c|c}
\hline \multirow{3}{*}{ NÍVEL } & \multirow{2}{*}{$\begin{array}{c}\text { PONTOS MÉDIOS } \\
\text { OBTIDOS }\end{array}$} & 10 & 20 & 30 & 40 & 50 & 60 & 70 & 80 & 90 & 100 \\
\hline & 53 & & & & & & & & & & \\
\hline 2 (Iniciado) & 46 & & & & & & & & & & \\
\hline 3 (Padronizado) & 42 & & & & & & & & & & \\
\hline 4 (Gerenciado) & 46 & & & & & & & & & & \\
\hline 5 (Otimizado) & 36 & & & & & & & & & &
\end{tabular}

Fonte: Elaborada pelos autores.

Esse resultado gráfico indica que as organizações podem ser aderentes aos diversos níveis, mas a maturidade está mais bem representada pelo nível em que se obteve a maioria dos pontos, o que reflete o quão bem se posiciona nos quesitos daquele item. Para esclarecer, a aderência média identificada ocorreu no nível 2 (Iniciado) correspondente às questões de I a Io, que retratam a situação em que cenários foram criados e estão sendo incorporados para provocar a aprendizagem 
no contexto da organização (Chermack, 2005), mas ainda não existem grandes avanços em padronização, gerenciamento e otimização do processo.

Os resultados encontrados no grupo de organizações respondentes corroboraram ainda as afirmações de Porto et al. (20I0), tendo em vista que a maioria (9/13) pertence à administração pública direta e indireta e que os maiores níveis de maturidade foram alcançados também nesse segmento, conforme se observa pelos números dispostos na Tabela 2.

\section{TABELA 2}

NÍVEL DE MATURIDADE POR TIPO DE ORGANIZAÇÃO

\begin{tabular}{lcccc}
\hline SEGMENTO DE NEGÓCIO & $\begin{array}{c}\text { EMPRESA } \\
\text { PRIVADA }\end{array}$ & $\begin{array}{c}\text { ADMINISTRAÇÃO } \\
\text { INDIRETA }\end{array}$ & $\begin{array}{c}\text { ADMINISTRAÇÃO } \\
\text { DIRETA }\end{array}$ & $\begin{array}{c}\text { TERCEIRO } \\
\text { SETOR }\end{array}$ \\
\hline Regulação & - & 1,24 & - & - \\
\hline Desenvolvimento empresarial & - & - & - & 1,43 \\
\hline $\begin{array}{l}\text { Agricultura, pecuária e } \\
\text { extrativismo }\end{array}$ & - & 3,58 & - & 1,71 \\
\hline Serviços & - & 1,$86 ; 2,06$ & - & 3,17 \\
\hline Planejamento & - & - & 1,91 & - \\
\hline Bancos & - & 2,66 & - & - \\
\hline Judiciário & - & - & 3,44 & - \\
\hline Autoindústria & 3,44 & - & 4,$69 ; 4,85$ & - \\
\hline Defesa & - & - & - & - \\
\hline
\end{tabular}

Fonte: Elaborada pelos autores.

Ressalte-se também que os maiores níveis atingidos $(4,69$ e 4,85), ambos os níveis de excelência, ocorreram em órgãos nacionais de defesa, sendo uma delas uma Escola de Guerra, demonstrando a tradição em cenarização entre essas organizações que são reconhecidas como o berço da estratégia e dos estudos de cenários. Bons resultados $(3,44,3,44$ e 3,58) foram encontrados em três esferas analisadas (setor privado, administração direta e indireta), com destaque para uma organização do segmento da agroindústria, pecuária e extrativismo, entidade pioneira no uso de cenários no Brasil, que obteve o resultado de 3,58, o que representa boa maturidade, com aderência boa ao nível 4 (gerenciado). Resultados regulares foram obtidos por uma organização da indústria bancária e uma organização prestadora de serviços do terceiro setor $(2,66$ e 3,I7). 
Dentre as organizações respondentes, seis apresentaram resultados que variaram entre maturidade muito fraca e fraca em quase todos os casos (4/6). As respostas ao questionário indicaram que, tanto no âmbito da alta administração quanto da média gerência, o assunto é apenas conhecido e não existe estímulo formal para o uso desses conhecimentos. Essas organizações pertencem tanto ao terceiro setor quanto à administração direta e indireta.

De modo geral, o teste realizado também demonstrou o autoconhecimento das organizações pesquisadas quanto ao processo e à efetividade da metodologia para identificação da maturidade, pois os níveis identificados, na autodeclaração, conformam-se com o que foi obtido pela aplicação dos questionários. Em sete organizações, o nível declarado é um pouco maior que o encontrado, e, em seis, ocorre o inverso, o nível declarado é um pouco menor, em que apenas no caso (I) ocorreu diferença superior a um ponto, conforme Gráfico I.

\section{GRÁFICO I}

\section{COMPARAÇÃO ENTRE O NÍVEL ENCONTRADO}

E O AUTODECLARADO

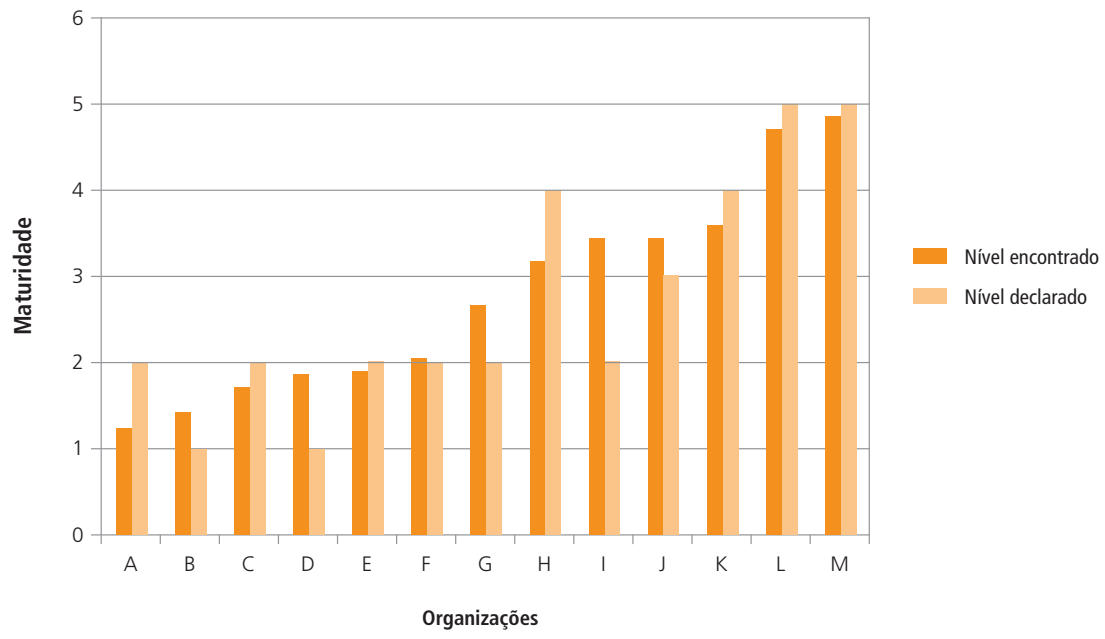

Fonte: Elaborado pelos autores.

\section{CONCLUSÃO}

A motivação inicial para realização deste trabalho surgiu da constatação de não haver, na literatura especializada, uma metodologia que objetivasse a avaliação da efetividade no emprego de estudos de cenários nas organizações. 
Da observação de Mietzner e Reger $(2005,2007)$ despertou-se para a necessidade de distinguir o processo do produto, e, a partir daí, surgiram outras perspectivas para desenvolver uma metodologia de avaliação, emergindo assim os modelos de maturidade como alternativas viáveis para avaliar o quão desenvolvido está o processo de cenários nas organizações.

Assim, como referenciais teóricos principais, utilizaram-se o trabalho de Bruin et al. (2005) para orientar os passos de construção do método, os critérios para distinção do processo da norma ISO/IEC I5504-5 (International Organization Standardization \& International Electrotechnical Comission, 2006), o MMGP de Prado (20I0) como modelo de referência, feita a devida aproximação entre os processos de gerenciamento de projetos e de cenários, e as leis de interação da teoria de planejamento de cenários de Chermack (2005, 2006, 20II) como subsídio primário para determinar os graus de maturidade.

Para atender ao objetivo específico de identificar os componentes e subcomponentes principais do processo de cenários que permitam avaliá-lo, foi realizada extensa revisão de literatura e consulta aos especialistas da academia nacional, resultando na identificação de que o macroprocesso se desenvolve em quatro etapas, também denominadas de dimensões: preparação, elaboração, produção do documento e utilização. Cada etapa é composta de componentes e subcomponentes que nortearam a elaboração do questionário de verificação da maturidade.

O segundo objetivo específico, que diz respeito à definição das métricas que indicam os estágios de maturidade organizacional em cenários, foi desenvolvido a partir da atribuição de pesos às respostas do questionário, gerando ao final uma pontuação que permite avaliar o perfil de aderência a cada nível de maturidade, bem como o amadurecimento de cada dimensão.

O terceiro objetivo relativo à aplicabilidade da metodologia indicou maturidade regular das organizações respondentes, revelando a predominância do assunto no setor público, com maiores níveis identificados em órgãos nacionais de defesa.

Conclui-se assim que os modelos de maturidade são meios alternativos para desenvolver uma forma de avaliação do processo de planejamento de cenários, pois procuram colocar o processo em relevo para evidenciar as dimensões que devem ser avaliadas, assim como os componentes e subcomponentes. Além disso, o modelo permite exercitar o pensamento acerca dos níveis de maturidade sobre quais são os estágios de desenvolvimento que o processo deve percorrer para ser considerado maduro, que, nesse método específico, evidenciou cinco estágios: inativo, iniciado, padronizado, gerenciado e otimizado.

Uma das limitações da pesquisa refere-se ao fato de representar uma versão inicial do método, portanto carente de testes mais robustos, posto que ele foi elaborado com apoio de literatura e peritos, e aplicado a um número de I3 grandes 
organizações, o que, ao mesmo tempo, revela um longo caminho para o estudo ora iniciado, permitindo que novas pesquisas sejam desenvolvidas para validação desse método.

Portanto, para futuros estudos, sugere-se a construção de um índice baseado em análises de organizações no Brasil e fora dele, com uso de técnicas de análise multivariada.

\section{PROPOSITION OF A METHOD TO EVALUATE THE MATURITY OF SCENARIO ANALYSIS INSIDE ORGANIZATIONS}

\section{ABSTRACT}

Scenario studies are developed by governments and organizations as a way to foresee possibilities, in order to develop specific strategies. Yet, there is little research in this field to evaluate the effectiveness of these studies; usually we can only find in the specialized literature attributes designed to evaluate the document of the scenario introduction. A possible approach to evaluate scenario quality would be the distinction between content, namely the scenario as a product itself, and the process that supports its elaboration. This research aimed to come up with a method to evaluate the maturity of scenario planning inside organizations. To do so, the major components and subcomponents of the scenario planning that enable us to evaluate them were identified; the metrics that indicate the stages of organizational maturity in scenarios were defined, and the application of the method in a selected set of Brazilian organizations was put into practice. As a possible alternative to ground the proposed method, the Project Management Maturity Model (PMMM) was used. A multimethodological, qualitative and interpretative study was undertaken, with multiples procedures used to collect and analyze data, including: literature review, interviews with experts on strategic scenarios and use of content analysis technique. As a result, we obtained a proposal for the evaluation of scenario planning in organizations that considered the following steps: preparation, development, document production and utilization. To determine the stage reached in scenarios, the following stages were considered: inactivity, initiation, standardization, management and optimization, culminating in the following maturity levels: very poor, poor, regular, good, great and excellent. The application of this method with thirteen Brazilian organizations identified regular maturity, unveiling the predominance of this subject in the public sector, with the highest levels observed in national 
defense organizations. The study offers contributions to the academic and professional fields. For the first it adds new knowledge represented by the proposal for the evaluation of the scenario planning, while for the second it provides a methodology that allows the execution of diagnosis of scenario-based processes to the organizations and consultancies, as well as the proposition of actions directed to improve objectively identified gaps.

\section{KEYWORDS}

Scenarios. Strategy. Processes. Project management. Organizational maturity.

\section{PROPUESTA DE UN MÉTODO PARA EVALUAR LA MADUREZ DEL PROCESO DE ESCENARIOS EN LAS ORGANIZACIONES}

\section{RESUMEN}

Estudios de escenarios son desarrollados por gobiernos y organizaciones como forma de vislumbrar futuros posibles y así realizar el diseño de sus estrategias. Sucede que hay pocas pesquisas que evalúen la efectividad de esos estudios. Normalmente lo que se encuentra en la literatura son atributos destinados a evaluar el documento de presentación del escenario. En ese sentido, un abordaje posible es la distinción entre el contenido, o sea, el producto escenario, propiamente dicho y el proceso que da soporte a su elaboración. En este contexto teórico, la investigación tuvo como objetivo proponer y aplicar un método para evaluar la madurez del proceso de escenarios en las organizaciones. Para ello se identificaron los componentes y subcomponentes principales del proceso de escenarios que permitan evaluarlos; se definieron las métricas que indiquen las etapas de madurez organizacional en escenarios; y se realizó un ejercicio de aplicación del método por intermedio de investigación en un conjunto de organizaciones brasileñas seleccionadas. Como alternativa posible para basar el método propuesto se utilizó el Modelo de Madurez en la Administración de Proyectos (MMAP). Así, se llevó a cabo un estudio multimetodológico, cualitativo e interpretativo para la colecta e interpretación de los datos, compuesto de: investigación bibliográfica, entrevistas con expertos del medio académico y uso de técnica de análisis de contenido. Como resultado, se obtuvo una propuesta de evaluación del proceso de escenarios en las organizaciones considerando las etapas: preparación, elaboración, producción del 
documento y utilización. Para determinarse cuál es el nivel alcanzado en escenarios, ellos fueron divididos en: inactivo, iniciado, estandarizado, administrado y optimizado, culminando en los niveles de madurez muy débil, débil, regular, bueno, óptimo y excelente. El ejercicio de aplicación del método con trece organizaciones brasileñas identificó madurez regular, revelando el predominio del tema en el sector público, con mayores niveles observados en órganos nacionales de defensa. El estudio trae contribuciones a los campos académico y profesional, pues al primero añade un conocimiento nuevo, representado por una propuesta de evaluación del proceso de escenarios, mientras que para el segundo pone a disposición de las organizaciones y de las consultorías una metodología que permite la realización de diagnóstico del proceso basado en escenarios, así como la proposición de acciones dirigidas para mejorarlo a partir de las lagunas objetivamente identificadas.

\section{PALABRAS CLAVE}

Escenarios. Estrategia. Procesos. Gestión de proyecto. Madurez organizacional.

\section{REFERÊNCIAS}

Barbandere, L., \& Iny, A. (2010). Scenarios and creativity: thinking in new boxes. Technological Forecasting \& Social Change, 77(9), I506-1512.

Bardin, L. (2009). Análise de conteúdo. Lisboa: Portugal: Edições 70.

Bido, D. de S., Godoy, A. S., Araujo, B. F. von Borrell de, \& Louback, J. C. (2010). Articulação entre aprendizagens individual, grupal e organizacional. Revista de Administração Mackenzie, 11(2), 68-95. Bishop, P. (200I, June). Forefront: a yardstick too far? Foresight, 3(3), I63-167.

Bood, R. P., \& Postma, T. J. B. M. (I998). Scenario analysis as a strategic management tool [Research report SOM 9805]. University of Groningen, Groningen, Netherlands.

Bouer, R., \& Carvalho, M. M. (2005, setembro/dezembro). Metodologia singular de gestão de projetos: condição suficiente para a maturidade em gestão de projetos? Revista Produção, 15(3), 347-36I. Bruin, T., Freeze, R., Kulkarni, U., \& Rosemann, M. (2005, 29 November-2 December). Understanding the main phases of developing a maturity assessment model. Proceedings of the $\mathrm{I} 6 \mathrm{th}$ Australasian conference on information systems. AISel, Io.

Buarque, S. C. (2003). Metodologia e técnicas de construção de cenários (Textos para discussão, n 939). Brasília: Ipea.

Canépa, P. C. V., Rigoni, E. H., \& Brodbeck, A. F. (2008). Práticas de alinhamento estratégico: um estudo exploratório em organizações industriais e de serviços. Revista de Administração Mackenzie, 9(I), I07-I29.

Chermack, T. J. (2005). Studying scenario planning: theory, research, suggestions and hypotheses. Technological Forecasting and Social Change, 72(I), 59-73. 
Chermack, T. J. (2006). Assessing the quality of scenarios in scenario planning. Futures Research Quarterly, 22(4), 23-35.

Chermack, T. J. (20II). Scenario planning in organizations: how to create, use, and assess scenarios. San Francisco: Berrett-Koehler.

Chermack, T. J., \& Merwe, L. (2003, June). The role of constructivist learning in scenario planning. Futures, 35(5), 445-460.

Fahey, L., \& Randell, R. (I998). Learning from the future. New York: Wiley.

Godet, M. (2000). The art of scenarios and strategic planning: tools and pitfalls. Technological Forecasting and Social Change, 65(I), 3-22.

Godet, M. (2010). Future memories. Technological Forecasting and Social Change, 77(9), I457-1463. Godet, M., \& Durance, P. (20II, setembro 2I). A prospectiva estratégica: para as empresas e os territórios. 20II. Recuperado em 23 setembro, 20I2, de http://en.laprospective.fr/dyn/traductions/ contents/findunod-godet-durance-ext-vpt.pdf.

Harrington, H. J. (2006). Process management excellence: the art of excelling in process management. Quebec: Hardcover.

Harrison, P. D. (2006). Análise e resultados da aplicação de modelos de maturidade em gerenciamento de projetos em uma organização: um estudo de caso. Dissertação de mestrado, Universidade de São Paulo, São Paulo, SP, Brasil.

Heinecke, A., \& Schwager, M. (I995). Die szenario-technik als instrument der strategischen planung. Germany: Braunschweig.

Huff, A. S. (I990). Mapping strategic thought. California: Willey.

International Organization Standardization, \& International Electrotechnical Comission (2006). ISO/IEC 15504-5: information technology - process assessment - part. 5: an exemplar process assessment model. Geneva: ISO.

Kerzner, H. (2006). Project management: a systems approach to planning, scheduling, and controlling (9th ed.). Ohio: John Wiley \& Sons.

Malhotra, N. K. (2006). Pesquisa de marketing: uma orientação aplicada (4a ed.). Porto Alegre: Bookman.

Marcial, E. C. (20I2). Gestão estratégica da informação e inteligência. São Paulo: Saraiva.

Mietzner, D., \& Reger, G. (2005). Advantages and disadvantages of scenario approaches for strategic foresight. International Journal of Technology Intelligence and Planning, 1(2), 220-239.

Mietzner, D., \& Reger, G. (2007). Future scenarios of the technological knowledge generation by multinational enterprises. Journal Technology of Intelligence and Planning, 3(2), I4I-156.

Mintzberg, H., Ahlstrand, B., \& Lampel, J. (20I0). Safári de estratégia: um roteiro pela selva do planejamento estratégico (2a ed.). Porto Alegre: Bookman.

Mintzberg, H., Lampel, J., Quinn, J. B., \& Ghoshal S. O processo da estratégia: conceitos, contextos e casos selecionados (4a ed.). Porto Alegre: Bookman, 2006.

Moraes, N. M., \& Forte, S. H. A. C. (20I2). Uma proposta de avaliação da maturidade do processo de cenários nas organizações. Anais do Encontro da Anpad, Rio de Janeiro, RJ, Brasil, 36.

Morgan, G. (I996). Imagens da organização. São Paulo: Atlas.

Neilson, R. E., \& Wagner, C. J. (2000, January/February). Strategic scenario planning at CA International. Knowledge Management Review, 12, 4-2I. 
Pishvaee, M. S., Fathi, M., \& Jolai, F. (2008). A fuzzy clustering-based method for scenario analysis in strategic planning: the case of an Asian pharmaceutical company. Journal of Business Management, 39(33), 2I-32.

Porto, C. A. F., Marques, E., \& Santos, A. B. A. (20I0). Prospective in Brazil: the power to build the future. Technological Forecasting and Social Change, 77(99), I550-1558.

Postma, J. B. M. T., \& Liebl, F. (2005). How to improve scenario analysis as a strategic management tool? Technological Forecasting and Social Change, 72, I6I-I73.

Prado, D. (20I0). Maturidade em gerenciamento de projetos (2a ed.). Minas Gerais: INDG-Tecs.

Project Management Institute (20I2). A guide to the project management body of knowledge (5th ed.). USA: PMI.

Ratcliffe, J. (2004). Scenario planning: an evaluation of practice. Futures Research Quarterly, 4(I9), 5-20. Ratcliffe, J. S. (2007). Challenges for corporate foresight: towards strategic prospective through scenario thinking. Foresight, 8(I), 39-54.

Rosemann, M., \& Bruin, T. (2005, May). Towards a business process management maturity model. Proceedings of the European Conference on Information Systems, Regensburg, Germany, I3.

Roubelat, F. (2000). Scenario planning as a networking process. Technological Forecasting and Social Change, 65(I), 99-II2.

Roubelat, F. (2009, February). Scenarios in action: comments and new directions. Journal of Futures Studies, 13(3), 93-98.

Schoemaker, P. J. H. (I998). Twenty common pitfalls in scenario planning. In L. Fahey \& R. M. Randall. Learning from the future (pp. 422-43I). New York: John Wiley \& Sons.

Schoemaker, P. J. H. (2004). Using scenarios in strategic planning. In: A. Daemmrich (Ed.). R\&D Meets M\&A (pp. 8I-90). Philadelphia: Chemical Heritage Press.

Schoemaker, P. J. H. (2005). Forecasting and scenario planning: the challenges of uncertainty and complexity. In D. J. Koehler \& N. Harvey (Eds.). Handbook of judgment and decision making (pp. 274-296). Malden: Blackwell.

Siqueira, J. (2005). O modelo de maturidade de processos. Nucleando Qualidade, 11(45), 4.

Snyder, S. A., \& Schoemaker, P. J. H. (2009) Strategic Radar: Scenario-based Monitoring and Scanning to Sense and Adapt to External Signals, Chapter 3. In Building Strategic Concepts for the Intelligence Enterprise, published by the Office of the Director of National Intelligence in 2009 and The Need to Reorganize the Intelligence Community, Studies in Intelligence published by the Central Intelligence Agency (pp. 75-93).

Sohail, I. (2002, April). Reductionism or layered complexity, the future of future studies, Futures, 34(3-4), 295-302.

Van Der Heijden, K. (2004, March). Can internally generated futures accelerate organizational learning? Futures, 36(2), I45-I59.

Van Der Heijden, K. (2005). Scenarios: the art of strategic (2nd ed.). Hoboken, NJ: Conversation.

Van Der Heijden, K. (2009). Scenarios planning. In T. M. Williams, K. Samset \& K. J. Sunnevag. Making essential choices with scant information (pp. 68-74). New York: Palgrave MacMillan.

Vergara, S. C. (2013). Projetos e relatórios de pesquisa em administração (I4a ed.). São Paulo: Atlas. 